\title{
The Teachers' Scientific Competence Profile Based on Higher Order Thinking Skills (HOTS) Perspective
}

\author{
Eka Danti Agustiani ${ }^{1}$, Nuryani Y. Rustaman ${ }^{2}$, Ana Ratna Wulan ${ }^{3}$ \\ \{kadantiani@gmail.com ${ }^{1}$, nuryanirustaman@upi.edu ${ }^{2}$, anaratnawulan@gmail.com ${ }^{3}$ \} \\ Science Education Programme of School of Postgraduate Universitas Pendidikan Indonesia ${ }^{1,2,3}$, \\ Jl. Dr. Setiabudi 229, Bandung, Indonesia
}

\begin{abstract}
The scientific competence indicators used by OECD in PISA year 2015 are (1) describe phenomena scientifically, (2) design and evaluate scientific inquiry, and (3) interpreting data and evidence scientifically. Those indicators are compatible with HOTS perspectives as they need the three highest cognitive process dimension namely analyze, evaluate and create. To fostering students' scientific competency in science learning, teachers must be mastering it first. This study aims to get the teachers' scientific competence's profile based on OECD indicators in HOTS' perspective. From written test done by teachers, it was found that capability in performing those three scientific competence indicators are still in less qualified.
\end{abstract}

Keywords: Teacher; Scientific competence; HOTS

\section{Introduction}

In science practice, scientific competence is important because of its relationship with the main cognitive abilities such as inductive and deductive reasoning, system thinking, critical decision, information transformation, constructing and communicating argument based on data, thinking in scale model and using science [1]. The aspects of scientific competence which were assessed by Organisation for Economic Co-operation and Development (OECD) in Programme for International Student Assessment (PISA) year 2015 are explained phenomena scientifically, evaluate and design scientific inquiry, and interpret data and evidence scientifically. In science practice, scientific competence is important because of its relationship with the main cognitive abilities such as inductive and deductive reasoning, system thinking, critical decision, information transformation, constructing and communicating argument based on data, thinking in scale model and using science [1]. Those indicators of competence confirm with higher-order thinking skills' (HOTS) definition by Brookhart [2], since they supporting transfer process of knowledge and skills, applying critical thinking and generate problem-solving. The knowledge about science aspect covering comprehension on main facts and concepts, scientific theory's explanation about nature and technology artifacts, the procedure of gaining knowledge, and understand epistemic knowledge. Meanwhile, the aspect of attitude towards science is a set of attitudes that indicate interest in science and technology, science values, appropriate investigation approach, as well as perception and awareness about environmental issues. Therefore, mastery of scientific competence 
Teachers play important roles in the implementation of the curriculum [3], as well as elementary school teachers in implementing an integrated curriculum included science in it. The ideal role of teachers is to guide their students in solving problems and conducting scientific projects, while books and subjects are considered as instruments of the learning process, not as the main source of knowledge [4]. However, the study of elementary school teachers' development related to science education is still rarely found. Perceptions and positive attitudes teachers towards learning science are still high in the context of integrative learning [5]. Elementary school teachers need to have adequate scientific competence when teaching using a scientific approach so that students succeed in achieving the target of scientific competence as well. Prospective primary school teachers have more positive emotions and beliefs to succeed if they teach the fields of biological and geological sciences, rather than physics and chemistry [6].

The aim of this study is to obtain data on elementary school teachers' scientific (as the first involved teachers in basic science education) competence profile. This paper revealed profiles of elementary school teachers' scientific competence based on the three aspects of scientific competence used by Organisation for Economic Co-operation and Development (OECD) in Programme for International Student Assessment (PISA) year 2015. The study intended to be the basis of the teacher development recommendations in basic science education.

\section{Method}

As this study concerned with basic science education, the subjects were 35 teachers who are in charge of the upper level of elementary schools. The range of teaching experience of subject teachers is varied which then grouped into 8 months to 11 years (16 persons) and 12 years to 36 years (19 persons) teaching experiences. Two of them hold a master's degree and others are bachelor degrees from various subjects. A written problem set was given to the teachers without prior notice or debriefing but only equipped with guidance to do the test. This is important since we wanted to identify the real up to dated data of competence' profile, without any initial treatment.

The written problem set consists of three items in essay format to challenge the teachers to perform the scientific indicators; (1) making a concept map based on a provided text, (2) design and evaluate a simple science inquiry and (3) interpreting tables of data. Rather than provided blanks for free answers, the concept map used to examine the scientific competence's aspect of teachers in explaining phenomena scientifically. Concept maps are valuable tools for visualizing information in the mind and they provide gateways to meaningful learning [7]. The text provided as a conceptual base titled Rumah Adat Sunda, which is placed as the phenomena to be explained. The text is describing a model of Sundanese traditional houses, consist of a good deal of information related to the science context. In their concept map, teachers could show their ability in explaining contextual science information by organized them scientifically, including making as many as expected reasonable links among the information. The categories used to assess the concept map are type Net, Chain and Spoke [8]. These simple categories are used since almost all of the subject teachers have never practiced, or even know about how to make a concept map. Just to make the instruction more clear, an example of concept map type Net about another topic (Makanan Sehat) is given in the problem sheet, without the underlying text. 
To identify the competence's aspect of design scientific inquiry, subject teachers must design an inquiry plan to test a hypothesis. The chosen inquiry is simple and possible to be carried out in elementary school, which is checking the volume of water with melting ice in it. The use of an alternative variable was also expected to be seen in the design. Two data table is given in the third part of the problem set, consist of some information regarding daily weather in Bandung municipality in the previous two years given to subject teachers to be interpreted. The first table represents data of temperature, humidity, sun-exposed, wet days and the second table gave data of the wind velocity. Teachers must be determined when the rainy, dry and transition seasons occurred. By that written task, the competence to interpret data and evidence scientifically was observed.

\section{Result and Discussion}

Written test results considered to detect the level of scientific competence of teachers are shown in Table 1.

\subsection{Explaining phenomena scientifically using a concept map}

There were five teachers (14\%) still looked like they have no idea how to construct their re-explanation for written described phenomena into a map form, though the Net type has given as an example (shown just before the Rumah Adat Sunda text). Four teachers (12\%) had tried to classify their explanation in a map form without any hierarchical structure and connection among subtopics (type Spoke), while 57\% (20 teachers) already made the hierarchical structure (type Chain). This result (see Table 1) parallels with a study result that both experts and novices in concept maps embraced deductive reasoning and preferred hierarchical type [7]. Even only with one or two connections, six teachers (17\%) made concept map type Net that is represented their comprehension, critical thinking, and creativity deeper than the other subject teachers. A concept-map with the Net type represents meaningful learning [8].

Table 1. The Level of scientific competence.

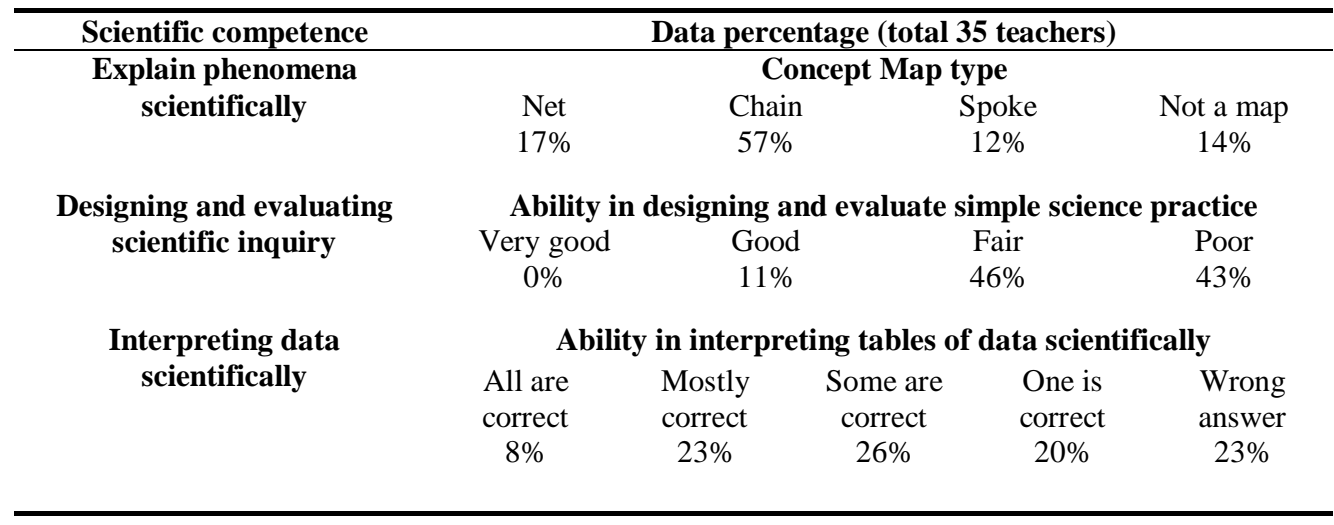


Logical reasoning will be used in pursuing the acquisition of additional information to illustrate the links between concepts, throughout the process of concept mapping [9]. Therefore, a good concept map is one of the scientific explanation forms. The ability to construct a good concept map indicates one aspect of scientific competence viz explaining phenomena scientifically. A concept map is a visual representation of knowledge, which is one of a helpful tool to visualize concepts, gain oversight of complex issues, capture global view by define and synthesis links, connections, approaches, and diagnosis [10]. Many studies tried to use concept-map as a tool in building and assessing understanding, critical thinking, pedagogical content knowledge, creativity, metacognitive, and network data [9-15]. All of those built and assessed cognitive objects are in higher-order thinking skills' (HOTS) scope. The more HOTS engaged, the more complex logical correlation among concepts can be made on a map.

Regardless of the less experienced in developing concept maps, these results indicate that elementary school teachers still lack skills to provide comprehensive explanations, including those related to science. This situation must be a serious concern because the teachers in elementary schools even have to deliver subjects in an integrated manner (thematic form). Supporters of integrated learning believed that schools can prepare their students to be citizens who are able to make decisions in a complex global world when they provide opportunities for their students to integrate and apply knowledge across subjects [16-18]. The purpose will only be achieved if teachers success blend the topics learned meaningfully. If the topics are related to science, the explanation which is the basis of learning must be conveyed scientifically too.

\subsection{Designing and evaluating scientific inquiry}

The competence's indicator of ability in design and evaluate scientific inquiry of 15 elementary teachers (43\% of participants) are still poor, provided false design and false scientific aspect. Only four teachers $(11 \%)$ were able to provide fit inquiry design with its scientific aspects but without any supporting scheme or images. Almost half of the teachers (46\%, 15 participants) only correct in one of their designs or scientific aspect of the inquiry.

Some studies have shown that teachers in elementary schools still have a low attitude towards science learning because of their educational background gave inadequate experiences in conducting scientific research activities [19-20]. That is one reason which makes science learning in elementary schools commonly still deliver in knowledge-based and relies on guidance and memorization. Despite the teachers guided by the National Curriculum's Teacher Book, unfortunately, most of them conduct the class activities just like using the cook recipes, lack of exploring the cognitive process within it. Instead, the tendency to just follow the example activities in the Teacher Book made teacher's critical thinking and creativity in designing and evaluating their scientific inquiry also allegedly not developing. Just imitating the exemplified activities become not optimal in exploring higher-order thinking skills (HOTS) both for teachers and students. This study's result confirms the suspected condition.

In the inquiry-based science learning (IBSL) and integrated learning of science, technology, engineering and mathematics (STEM), scientific inquiry and designing are the cores. An inquiry is used to answer the question and test the hypothesis in IBSL, while designing is the first step of engineering in STEM. Both are requiring HOTS to be implemented. Teacher participation determines the success of the IBSL and STEM teaching and learning process significantly [21], [22-23]. Therefore, it is very important to always explore and check how the teachers them self comprehend and mastering required HOTS before they conduct the IBSL and STEM teaching and learning process (even if just using 
provided learning scenarios) and assessed their student's HOTS. Moreover, the teacher development program must concern to improving HOTS capacity of teachers as indicated in scientific competence.

\subsection{Interpreting data and evidence scientifically}

Three teachers (8\%) succeeded in answering three pairs of questions about determination dry season and wet season periods correctly. The other 24 teachers $(46 \%)$ were able to answer at least one pair of questions correctly. From eight teachers $(23 \%)$ who gave the wrong answer, there was one teacher who even gives answers based on his assumptions, rather than referred to the available data. In this third part of the problem set, the competence to making a prediction is not yet detected. Even though, it can be assumed that respondents must read the pattern of the rainfall, wet days frequency, and wind velocity to determine the transition period. But there were still a few teachers who use the data of wind in the second table, especially to state when the transition season occurred. This was alleged because the teachers paid little attention to the conditions of the wind during the transition season.

Science will always be connected with valid and reliable data. Data literacy is the ability to understand and use data effectively to make decisions. Interpreting data is one of the needed skill components in data literacy, besides developing a hypothesis, identify problems, and determine, plan, implement, and monitor courses of action [11]. Interpreting data scientifically means to analyze and evaluate data, claims, and arguments in a variety of representations and draw appropriate scientific conclusions [1]. Those are represented HOTS both in the cognitive process analyze, evaluate and create [24] and higher-order thinking skills (HOTS) definition category as critical thinking [2]. Without HOTS even scientific data will not be meaningful to be used. Ironically, teachers and educators found as subjects who still less in literacy awareness and less qualified in using data [25-26].

\section{Conclusions and recommendations}

Even the study just made a portrait of teachers' scientific competence's in Organisation for Economic Cooperation and Development (OECD) indicator frames, many aspects can be learned from the result. The written tasks which are used to assess the scientific indicator performances needed higher-order thinking skills (HOTS) to be done, thus it is relevant to discuss the result in HOTS' perspective. Making a meaningful scientific network in a concept map was noted less mastered by teachers. It can indicate that the ability to explain phenomena scientifically still needs to be explored and improved. In HOTS's perspective, it will especially deal with cognitive process dimensions of analyze and create and term transferring knowledge. The poor capability to designing and evaluating scientific inquiry must be correlated with the weakness to analyze, evaluate and create in cognitive process dimensions, whereas critical thinking and problem-solving capacity also still less honed. Since only $8 \%$ of teachers could answer correctly to all questions which are needed to interpret data scientifically, the cognitive process dimensions of analyzing and evaluation must be a concern, regarding the availability of critical thinking.

Scientific competence is very important and can especially be developed in science-based learning. To foster student scientific competence, teachers must first master these competencies, including elementary school teachers through science-based thematic learning. 
The findings of this study show that the scientific competencies of elementary school teachers still need to be fostered through various forms of professional development programs, both through formal education for pre-service teachers, in-service training, activities in the teacher working group and experts assistance. Moreover, the scientific competence of teachers in higher-level schools (lower and higher secondary schools) are needed to be investigated as well. All of the efforts must be supported by a suitable learning and assessment system both for teachers and students. If the learning and assessment based on HOTS, hence scientific competence can be expected to be developed.

Acknowledgments. This research is part of a program funded by the Office of Planning and Foreign Cooperation (BPKLN) of the Ministry of Education and Culture Republic of Indonesia through the Beasiswa Unggulan scheme.

\section{References}

[1] OECD, PISA 2015 Assessment and Analytical Framework: Science, Reading, Mathematic, Financial Literacy and Collaborative Problem Solving, revised edition, PISA, OECD Publishing, Paris (2016)

[2] Brookhart, S. M.: , How to Assess Higher-Order Thinking Skills in Your Classroom, (Alexandria, Virginia USA: ASCD). (2001)

[3] Darling-Hammond, L., and Young, P.: Defining "highly qualified teachers": What does "scientifically-based research" actually tell us? Educational Researcher, December, 13-25. (2002)

[4] Osborne, J.: Teaching scientific practices: Meeting the challenge of change. Journal of Science Teacher Education, 25, 177-196. (2015)

[5] Milner, A. R., Sondergeld, T. A., Demir, A., Johnson, C. C., and Czerniak, C. M.: Elementary Teachers' Beliefs About Teaching Science and Classroom Practice: An Examination of Pre/Post NCLB Testing in Science. Journal of Science Teacher \& Education, 23, 111-132. (2012)

[6] Brigido, M., Borrachero, A. B., Bermejo, M. L., and Mellado, V.: Prospective primary teachers' self-efficacy and emotions in science Teaching. European Journal of Teacher Education, 36(2), 200 217. (2013)

[7] Dogusoy-Taylan, B., and Cagiltay, K.: Cognitive analysis of experts' and novices' concept mapping process: An eye tracking study. Computer in Human Behavior, 36, 82-93. (2014)

[8] Kinchin, I. M., David, B. H., and Adams, A.: How a qualitative approach to concept map analysis can be used to aid learning by illustrating patterns of conceptual development. Educational Research, 42(1), 43-57. (2000)

[9] Bittencourt, G. K. G. D., Nobrega, M. M. L., Medeiros, A. C. T., and Furtado, L. G.:Concept maps of the graduate programme in nursing: experience report. Rev Gaucha Enferm, 34(2), 172-176. (2013)

[10] Jain, G., P., Gurupur, V. P., Schroeder, J. L., and Faulkenberry, E. D.: Artificial intelegencebased student learning evaluation: A concept map-based approach for analyzing a student's understanding of a topic. IEEE Transaction Learning Technologies, 7, 267-279. (2014)

[11] Lin, C. F., Yeh, Y., Hung, Y. H., and Chang, R. I.: Data mining for providing a personalized path in creativity: An application of decision trees. Computers and Education, 68, 199-210. (2013)

[12] McLinden, D. :Concept maps as network data: Analysis concept map using the methods of social network analysis. Evaluation and Program Planning, 36, 40-48. (2013)

[13] Dabbagh, N. : Concept mapping as a mindtool for critical thinking. Journal of Computing in Teacher Education, 17(2), 16-23. (2014)

[14] Mok, C. K. F., Whitehill, T. L., and Jodd, B. J. : Concept map analysis in the assessment of speech-language pathology students' learning in a problem-based learning curriculum: A longitudinal study. Clinical Linguistics \& Phoenetics, 28(1-2), 83-101. (2014) 
[15] Chan, Z. C. Y.: A qualitative study on using concept maps in problem-based learning. Nurse Education in Practice, 24, 70-76. (2017)

[16] Cervetti, G. N., Barber, J., Dorph, R., Pearson, D., and Goldschmidt, P. G. : The Impact of an Integrated Approach to Science and Literacy in Elementary School Classrooms. Journal of Research in Science Teaching, 49(5), 631-658. (2012)

[17] Drake, S. M., and Reid, J. L.: Integrated Curriculum as an Effective Way to Teach 21st Century Capabilities. Asia Pasific Journal of Educational Research, 1(1), 31-50. (2018)

[18] Ferguson-Patrick, K., Reynolds, R., and Macqueen, S. : Integrating curriculum: a case study of teaching global education. European Journal of Teacher Education, 41(2), 187-201. (2018)

[19] Jarrett, O. S.: Science interest and confidence among preservice elementary teachers. Journal of Elementary Science Education, 11(1), 47-57. (1999)

[20] Murphy, C., and Smith, G.: The impact of a curriculum course on pre-service primary teachers'science content knowledge and attitudes towards teaching science. Irish Educational Studies, 31(1), 77-95. (2012)

[21] Alake-Tuenter, E., Biemans, H. J. A., Tobi, H., Wals, A. E. J., Oosterheert, I., and Mulder, M., Inquiry-Based Science Education Competencies of Primary School Teachers: A literature study and critical review of the American National Science Education Standards. International Journal of Science Education, 34(17), 2609-2640. (2012)

[22] Ireland, J. E., Watters, J. J., Brownlee, J., and Lupton, M. : Elementary teacher's conception of inquiry teaching: messages for teacher development. Journal of Science Teacher Education, 23, 159175. (2012)

[23] Cotabish, A., Dailey, D., Robinson, A., and Hughes, G. : Effects of a STEM Intervention on Elementary Students' Science Knowledge and Skills, School of Science and Mathematics, 113(5), 215-226. (2013)

[24] Krathwohl, D. R.: A revision of Bloom's taxonomy: An overview. Theory into Practice, 41(4), 212-218. (2002)

[25] Mandinach, E. B., and Gummer, E. S.: What does it mean for teachers to be data literate: Laying out the skills, knowledge, and dispositions. Teaching and Teacher Education, 60, 366-376. (2016)

[26] Mandinach, E. B., and Jimmerson, J. B. : Teachers learning how to use data: A synthesis of the issue what is known. Teaching and Teacher Education, 30, 1-6. (2016) 